\title{
Cultivation of Performing Skills in the Practice of Vocal Music Art
}

\author{
Jie Tong \\ Aba Teachers University, Aba, 623002
}

Keywords: performing skills, practice of vocal music art, expression with excellent voice and affection, artistic appeal

\begin{abstract}
In human history, vocal music art has developed into an art discipline with its own artistic value through practice, accumulation and renewal. In many performing arts, as the most authoritative form of art performance, vocal music art performance has the characteristics of popularity and appreciation, which can directly resonate with the viewers and fully display the beauty of art. If performers want to show the perfect stage effects and excellent singing standards, mastering performance skills is particularly important. They should also pay more attention to study and practice, accumulate experience on stage, and cultivate performing skills in vocal music art practice. This paper explores and expounds how to train performing skills in vocal music practice.
\end{abstract}

\section{Introduction}

With the development of the times, performing skills of vocal music also are required to keep pace with the times. Moreover, with the development of science and technology, vocal music is not only confined to major concerts. People have a deeper understanding of vocal music and put stricter requirement for vocal music. Therefore, in vocal music practice, performers need to pay more attention to the training of performing skills, so that the performance will become more rich, artistic and touching with more artistic appeal. The practice of vocal music art cannot be separated from performance. Perfect integration of performance and vocal music can better promote the emotional expression of vocal music art and better show the charm of the stage.

\section{General Situation of Vocal Music Performance}

Vocal music is a form of human singing, mainly with vocal cords, coupled with oral cavity, nasal cavity and tongue, so that the breath changes, making a pleasant, continuous and rhythmic sound. On the division of vocal music, according to the difference of pitch and timbre, women can be divided into soprano, mezzo-soprano and bass, and men can be divided into tenor, baritone and bass. Vocal music also differs in singing, including bel canto, folk singing and popular singing. But in most cases, vocality means bel canto.

Performance is an important form of vocal art. Vocal artists are able to arouse the resonance of the audience and enhance the artistic expressiveness and appeal by fully studying and practicing vocal music and expressing it through performance. However, a good mastery of performing skills is indispensable to the excellent performance, which requires vocal art performers' appropriate eyes expressions, facial expressions and movements, which plays an indispensable role in the performance. That is to say, performers are not only required to sing well, but also to perform well. This worth the contemporary students' mastery and learning who major in vocal art. But nowadays there are a lot of vocal practice classes in college vocal music courses seldom involving performance, which leads to the performance skills of most students to be far from enough. But no matter in professional examination or commercial performance, as a singer, they inevitable need to step onto the stage and this is an important link. Therefore, increasing the practice of vocal music art and training of students' performing skills are the urgent problems to be solved in contemporary vocal music education. 


\section{Requirements of Performing Skills in Vocal Music Technology Practice}

A good work has its unique charm. When performing these works, vocal performers need to fully understand their meaning, and are not allowed to change the meaning and emotion of the original works. This requires that performers have a good artistic accomplishment and performing ability, which also means that performers need to have a strong understanding of the original works. First of all, vocal performers are required to fully understand the words and songs of the works, understand the intention of the original author on the basis of understanding the words and songs, get know the emotions, and deduce emotions the original author wants to express through superb performance skills. This asks vocal performers to be able to make full use of performance skills through their own expressions, body and etc. It is by no means a copy of the previous performance, but a performance with their own understanding, integrated with performing skills on the basis of understanding, so that words can be more artistic appealing, expressive and touching.

Andorr Frodos once said, "Great works are super-epochal”, meaning that excellent works can withstand the test of time in any era and passed down. So good music works will not be eliminated by the times, but on the contrary, it is eternal. While, the performance of music works is to be branded with the times. That is to say, the performance form and performance skills of excellent works will change with the development of the times, because with the passage of time and the development of the era, each performance will be changed on the basis of the original works combined with the characteristics of current era, and the emotions of works will become richer and richer, but all of which are presented through performers' understanding. In addition, the historical background and audience of each era are very different, which requires vocal performers to adapt to the development of the times and change the way they express their emotions, so as to better enrich the work and resonate with the audience.

Art originates from life and is higher than life. It is processed and created through imagination. Therefore, the performance of excellent works needs rich imagination and creativity, so as to express the connotation of vocal art works. Performers often give full play to imagination, and imagine themselves as the protagonist. With rich imagination, performance becomes richer. In order to achieve this, performers should immerse themselves in the artistic conception of the works, merge themselves, and use their imagination to express the artistic conception of the works through their own understanding and perception, and then release emotions, so as to enrich the emotions and contents of the works. They can also combine works with the times to enrich the contents of vocal music performance.

\section{Training of Performing Skills in Vocal Music Practice}

Eyes are windows to the soul. Whether a piece of work is devoted to rich emotions can be seen from eyes. Therefore, if you want to infect the audience, eyes must be sincere enough. Vocal performers do not need a lot of body movements, because vocal performance is based on sound. In this case, the expression of eyes is particularly important. Moreover, in vocal music performance, the audience uses their ears to listen, but they will not close eyes, so the expression of eyes can convey the audience performers' respect for the stage, and also arouse the audience's resonance for the contents of vocal music performance. In the performance, sad work requires a sad expression and look, and happy work needs a happy expression and look. Only in this way, can performers resonate with the audience, attract them and achieve successful performance.

The so-called sound expression, in other words, means that, in vocal performance, performers must not only focus on their own singing skills, but also pay attention to their emotional release. Without emotional singing, the best singing skills presented to the audience is just an unsuccessful and boring performance, failing to bring the audience a good audio-visual experience or arouse the audience's resonance. So how can they sing wonderfully with a silver voice and deep feeling? First of all, the mastery of vocal music singing skills is the foundation. Only through a large number of practices and mastery of a large amount of singing skills can performers offer emotional 
presentation. Secondly, in order to achieve good effects, it is a must to get familiar with the work, that is, have a profound understanding of the work. Only by understanding the contents of the work, performers can achieve the effect of empathy according to his own actual experience, so that the performance can resonate with the audience. Finally, to achieve perfect effect, it is required to bring performers themselves into the works, so that their true feelings can fuse with the contents and emotions expressed by the works together. After a thorough understanding, performers are able to sink into the artistic conception of the work, merges themselves, and then uses imagination to express the artistic conception based on their own understanding and perception according to the characteristics of the times, so as to achieve the fusion of feelings with themselves and the fusion of feelings with the work.

Vocal performers on the stage, is the focus of all the audience. In the center of the stage, the audience can see whatever action. When the performer on stage, his body movements is a part of the performance. So, corresponding body movements will greatly increase the stage effects and enhance the artistic appeal. When the body movements are cleverly combined with music and emotion, these body movements will enhance the emotional appeal of the work, get the audience going and produce resonance between the performance and the audience. Therefore, performers should pay attention to keep the harmony between action and music, as well as the flexibility and fluency of action. A good integration of music, emotion and atmosphere is conducive to the presentation of works and the success of performances.

People on stage for the first time are always nervous and overwhelmed, but after several times, they become experienced, so they are able to deal with accidents that may occur on the scene and find solutions. This requires performers to have a lot of stage experience, be able to adapt to the stage, and perfectly interpret their own works. Some inexperienced performers often tend to be out of tune or have broken sound. In order to avoid such a situation occurring again, they must constantly accumulate stage experience, so as to improve themselves. In addition to accumulating experience, they also need to have the psychological quality to promote the scene atmosphere. Some students' psychological quality is too low to driven the scene atmosphere, because they are fear of interaction with the audience, which explains why these performances are failure. For vocal music performers, in order to be ready for performance, they are proposed to often exercise themselves, constantly improve themselves in practice, accumulate experience, enhance psychological quality and make appropriate preparations.

At the beginning of creation, all works have specific roles assigned by the author. For example, in Forever Friendship, your role is a friend, so the emotion you need to express is the friendship between friends. Although with a strong flexibility, the role of performers can be switched arbitrarily compared with drama, film and so on, performers still have to act like actors in their roles. No matter how the role changes, they need to ensure that their emotions express what the works want to express.

\section{Conclusion}

The practice of vocal music art cannot be separated from performance. Perfect integration of performance and vocal music can better promote the emotional expression of vocal music art and better show the charm of stage. If performers want to show perfect stage effect, they must master performing skills. In order to cultivate performing skills in vocal music practice, they need to grasp the opportunity to perform, accumulate experience in practice, improve psychological quality, be able to cooperate with body movements, facial expressions, and driven the scene atmosphere by making full use of body movements, facial expressions and eyes, so that the audience will be mingled with the performance. Moreover, more attention should be paid to emotional input, so that rich emotion can move the audience. Performers can master performing skills as well as provide a successful performance. 


\section{References}

[1] Hang Tianhui. Analysis on the Cultivation of Performing Skills in Vocal Music Art Teaching [J]. Journal of Pu'er University, 2018 (04): 103-104.

[2] Mu Ziru. Exploration on the Fusion of Emotional Expressions and Skills Application in Vocal Music Performance [J]. Journal of Hubei Correspondence University, 2018,31(11): 193-194.

[3] Liu Yang. Way to Explore Vocal Music Performance: A Review of Zhao Feng’s "Vocal Music Performance and Theoretical Research under A New Vision" [J]. Journal of Linyi University, 2018,40 (01): 143-144.

[4] Wang Meijuan. Status and Importance of Vocal Skills in Vocal Music Art [J]. Voice of the Yellow River, 2017 (15): 98-99.

[5] Zhang Yan. Analysis of the Effective Application of Emotional Expression in Vocal Music Performance [J]. Voice of the Yellow River, 2015 (13): 87.

[6] Zhang Ge, Wang Zhaohui. On the Role and Value of Vocal Music Skills in Vocal Music Art [J]. Voice of the Yellow River, 2014 (17): 82.

[7] Wang Chunxia. On "Emotion” and "Skills” in Vocal Music Art [J]. Journal of Hebei Normal University for Nationalities, 2014, 34 (03): 71-72.

[8] Yan Lijuan. Interpretation of Modern Ethnic Vocal Music in Aesthetic Context-On the Performing Beauty of Chinese Ethnic Vocal Music Art [J]. Hunan Social Sciences, 2012 (02): 201-203.

[9] Yin Chunjing. On How to Better Stage Performance of Vocal Music Art [J]. Popular Literature and Art in Vocal Music, 2010 (21): 6-7. 